\title{
Leaf Diseases Classification on Peanut Leaves Based on Texture and Colour Features
}

\author{
Brahma Ratih Rahayu F. \\ Department of Electrical \\ Engineering, University of \\ Brawijaya \\ Malang, Indonesia
}

\author{
Panca Mudjirahardjo \\ Department of Electrical \\ Engineering, University of \\ Brawijaya \\ Malang, Indonesia
}

\author{
Muhammad Aziz Muslim \\ Department of Electrical \\ Engineering, University of \\ Brawijaya \\ Malang, Indonesia
}

\begin{abstract}
Peanuts are a food crop commodity that Indonesians widely consume as a vegetable fat and protein source. However, the quality and quantity of peanut productivity may decline, one of which is due to plant diseases. Efforts that can be made to maintain peanut productivity are the application of technology to detect peanut plant diseases early; thus, disease control can be carried out earlier. This study presents a technology development application, particularly digital image processing, to identify disease features of infected peanut leaves based on GLCM texture features and colour features in the HSV colour space and classified using the SVM method. The development of the SVM method that is applied is the Multiclass SVM with the DAGSVM strategy, which can classify more than two classes. Based on the experimental results, it confirms that the combination of HSV colour features and GLCM texture features with an angular orientation of 0 degrees and classified by the Multiclass SVM method with polynomial kernels produces the highest accuracy, i.e. $99.1667 \%$ for leaf spot class, $97.5 \%$ for leaf rust class, $98.8333 \%$ for eyespot class, $100 \%$ for normal leaf class and $100 \%$ for other leaf class.
\end{abstract}

Keywords: Peanut, GLCM, HSV, Multiclass SVM, DAGSVM

\section{INTRODUCTION}

Peanut (Arachis Hypogae L.) is one of the most common crops consumed by Indonesians, which benefits as a source of vegetable fat and protein. In addition, the benefits of peanuts are that they hold high economic value, which can be relied on as a crop to increase farmers' income. In increasing peanut productivity, several factors affect the quality and quantity of the results achieved, specifically pests, changing weather conditions, and plant diseases. Plant disease is an important limitation in peanut cultivation in Indonesia [1]. Thus far, identifying plant diseases is only by observing the external appearance of the plant. One other way that can be done is a lab test, particularly by isolating the pathogen associated with the symptoms of the disease with the tissue planting method. Then the sample will be incubated for 2-3 days and subsequently will be observed using a microscope to determine the morphological and physiological characters [2]. Although morphological and physiological characters are required during the initial study, this method is considered less efficient since it takes a longer time.

In order to contribute to maintaining peanut productivity, the use of technology can certainly be an alternative to be applied to peanut cultivation, especially for the introduction and control of plant diseases. Technology application that can be implemented is digital image processing. The application of digital image processing is used to identify the features of the image of leaves affected by the disease; thus, it can help identify peanut plant diseases early.

Several image processing techniques are feature extraction and classification. In feature extraction and classification, appropriate methods are needed in identifying diseases in peanut plants. Feature extraction techniques can be analysed through colour, shape, and texture. The feature extraction technique chosen in retrieving the features of peanut leaf plant disease is texture and colour. The Gray Level Co-occurrence
Matrix (GLCM) method is a method in texture feature extraction; this method was adopted because it has been proven to be an effective texture descriptor, simple method, easy to use, and has good accuracy and computation time [3]. In addition to texture feature extraction, colour feature extraction is also used in the HSV colour space. The HSV colour space was preferred because it consists of colours that can be captured by human vision. The classification technique used was the Support Vector Machine (SVM) method; this method can work well on high dimensional data sets. Only a selected number of data contributes to forming the model used in the classification [4]. The SVM method can only perform binary classification (two classes); thus, development was performed, i.e. the Multiclass SVM method.

Based on the description of the problem above, in identifying diseases in peanut plants, a combination of GLCM texture features and HSV colour features were used and classified using the Multiclass SVM method with the DAGSVM strategy.

\section{LITERATURE REVIEW}

Several previous studies regarding identifying plant diseases have weaknesses, such as identifying medicinal plant diseases using the LBP and FLBP methods, particularly in determining the grey pixel value threshold, which makes the presentation of its texture sensitive to noise [5]. Another study regarding the identification of soybean plant diseases based on texture features using the Gabor method shows that recognising disease features is highly dependent on delivering the correct value of the frequency and orientation parameters [6]. Research on disease identification through the combination of textural features with GLCM and colour features in the LAB colour space can provide an accuracy of up to $97 \%$ [7].

Research on the classification of rice plant diseases proves that the ANN classification provides an accuracy of $87.5 \%$ and the SVM classification provides an accuracy of $92.5 \%$ 
[8]. Another study, particularly the classification of cucumber leaf disease using M-SVM with the OAA strategy, recognised the disease well. In the OAA method, for class $\mathrm{N}$ problems $(\mathrm{N}>2$ ), two classes of SVM were formed. The first SVM was trained and labelled the sample in the first class as positive, and in the rest of the class, it was labelled negative. The OAA strategy has a disadvantage, i.e. the complexity of training because each $\mathrm{N}$ is trained with all available samples [9]. Another study, classification of types and phases of various malaria parasites used the OAO strategy, with an accuracy rate of $85 \%$ to $95.55 \%$ [10]. The OAO strategy has a disadvantages, which is that it requires more time in testing. Research [11], regarding the classification of textile motive using the M-SVM method, the results showed that using the DAGSVM strategy gave a better results when compared to OAA and OAO strategies. DAGSVM is applied to classify the types of electrocardiogram signals, the results show that DAGSVM provides better accuracy when compared to the KNN and ANN methods. Multiclass SVM method with the DAGSVM strategy, which can provide good accuracy and faster computation time. [12].

\section{METHOD}

In this study, a scheme was developed, i.e. the extraction process for the image features of infected peanut leaves using the GLCM method to determine the texture and colour space features of HSV to determine the colour features of each disease and classified using the M-SVM method. The process stages of this research consisted of image input, preprocessing, segmentation, feature extraction, and classification. Figure 1 shows the research methodology carried out in this study.

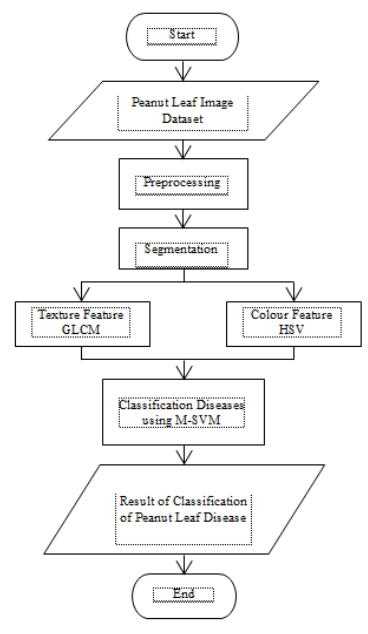

Figure 1. Research Method

\subsection{Image Input}

The image data used is the image of peanut leaves obtained from the image acquisition process. The image used is an image of RGB-level peanut leaves in .jpg format. The image resolution size is $4608 \times 3465$ pixels. The image of peanut leaves used consists of leaf spot class, leaf rust, eyespot, normal leaf, and other leaves.

\subsection{Preprocessing}

At this stage, the RGB input image was resized. The original RGB input image will be reset in resolution to $635 \times 439$ pixels. The resizing process aims to simplify the calculation process and reduce storage capacity and processing time.

\subsection{Segmentation}

Segmentation is the process of separating one object from another object or between objects and the background contained in an image. In this study, image segmentation was used to select the Region of Interest (ROI) on the leaf image of the peanut plant, which consists of several stages, i.e

1. Converting the image of peanut leaves in RGB format to a $\mathrm{LAB}$ image. The conversion of RGB images to $\mathrm{LAB}$ can be calculated using equation 1 [13].

$$
\begin{aligned}
& L^{*}=116 f\left(\frac{Y}{Y_{n}}\right)-16 \\
& a^{*}=500\left[f\left(\frac{X}{X_{n}}\right)-f\left(\frac{Y}{Y_{n}}\right)\right] \\
& b^{*}=200\left[f\left(\frac{Y}{Y_{n}}\right)-f\left(\frac{Z}{Z_{n}}\right)\right]
\end{aligned}
$$

In this matter, $f(q)$ is calculated as follow

$$
f(q)=\left\{\begin{array}{c}
q^{\frac{1}{3}}, \text { jika } q>0,008856 \\
7,787 q+\frac{16}{116}, \text { for another }
\end{array}\right.
$$

2. Clustering using the $\mathrm{K}$-means method on the $\mathrm{a}^{*}$ and $\mathrm{b}^{*}$ components of the LAB colour space. The K-means method works by partitioning $\mathrm{N}$ objects into $\mathrm{K}$ groups (clusters) in one group with the closest centroid. The calculation of the distance from each data to each centroid employs the Manhattan distance calculation, which can be calculated using equation 2 [14].

$$
d_{i j}=\sum_{k=1}^{n}\left(x_{i k}-y_{j k}\right)
$$

Where $d$ is the distance between $i$ and $j, i$ is cluster data center, $j$ is attribute data, $k$ is the symbol of each data, $n$ is the amount of data, $x_{i k}$ is the data in the centre of the $k$ cluster, and $y_{j k}$ is the data on each $k$ data.

3. Filling the object with the resulting image from the $\mathrm{K}$ means clustering process. The purpose of the object filling process is to fill the perforated objects.

4. Perform image subtraction, particularly reducing the image resulting from the K-means clustering and the resulting image from the filling object.

5. Perform a bwareaopen operation to remove objects with a small number of pixels; thus, the image segmentation results will be obtained.

\subsection{Feature Extraction}

Feature extraction is an important step in building classification and aims to extract relevant information that characterises each class. The purpose of feature extraction is to perform calculations and comparisons that can be used to classify the features of an image. Feature extraction has a significant role because the better the feature extraction, the higher the level of accuracy.

In this study, the feature extraction process was carried out to obtain the texture feature and colour feature of the image of the segmented peanut leaves. The texture feature used was the Gray Level Co-Occurance Matrix (GLCM) method. This method recognises texture features by calculating the spatial relationship between pixels in the image. The GLCM matrix is created by determining the relationship of pixels of various angular orientations and distances. Texture features extracted were angular second moment (ASM), contrast, inverse 
difference moment (IDM), correlation, entropy, variance, sum average, sum entropy, sum variance, difference entropy, and difference variance [15].

Angular second moment (ASM) is a measure of the homogeneity of an image. ASM is calculated using equation 3 .

$$
A S M=\sum_{i=0}^{N_{g}} \sum_{j=0}^{N_{g}} P\left(i_{s} j\right)^{2}
$$

Contrast is a measure of the varying intensity of the presence of an image or a measure of the spread of gray elements in an image. Contrast is calculated using equation 4.

$$
\text { Contrast }=\sum_{i=1}^{N_{g}} \sum_{j=1}^{N_{g}}(i-j)^{2} P(i, j)
$$

Inverse Difference Moment is used to measure homogeneity. The homogeneity in question is the local homogeneity of the observed images. IDM is calculated using equation 5.

$$
I D M=\sum_{i=0}^{N_{g}} \sum_{j=0}^{N_{g}} \frac{P(i, j)}{1+(i-j)^{2}}
$$

Correlation is a measure of linear dependence or the value of the gray level in the image. Correlation calculates the correlation between one pixel and another pixel. Correlation is calculated using equation 6 .

$$
\text { Correlation }=\sum_{i=0}^{N_{g}} \sum_{j=0}^{N_{g}} \frac{(i \times j) P(i, j)-\mu_{x} \mu_{y}}{\sigma_{x} \sigma_{y}}
$$

Entropy is used to measure gray level irregularity in the image. Entropy can be calculated using equation 7.

$$
\text { Entropy }=-\sum_{i=1}^{N_{g}} \sum_{j=1}^{N_{g}} p(i, j) \log [p(i, j)]
$$

Variance is used to measure the spread (related to the mean) of the gray level distribution. Variance is calculated using equation 8 .

$$
\text { Variance }=\sum_{i=1}^{N_{g}} \sum_{j=1}^{N_{g}}(i-\mu)^{2} P(i, j)
$$

Sum average is used to measure the average distribution of the number of gray levels in the image. Sum average is calculated using equation 9.

$$
\text { Sum Average }=\sum_{i=2}^{2 N_{g}} i p_{x+y}(i)
$$

Sum entropy is used to measure noise related to the gray level distribution in the image. Sum entropy is calculated using equation 10.

$$
\text { Sum Entropy }=-\sum_{i=2}^{2 N_{g}} p_{x+y}(i) \log \left\{p_{x+y}(i)\right\}
$$

Sum variance is used to measure the spread (concerning the mean) in distributing the amount of grayscale in the image. Sum variance is calculated using equation 11 .

$$
\text { Sum Variance }=\sum_{i=2}^{2 N_{g}}\left(i-\left[\sum_{i=2}^{2 N_{g}} i p_{x+y}(i)\right]\right)^{2}
$$

Difference entropy is used to measure noise associated with the distribution of differences in the gray level of the image. The entropy difference is calculated using equation 12 .

$$
\text { Difference Entropy }=-\sum_{i=0}^{N_{g-1}} p_{x-y}(i) \log \left\{p_{x-y}(i)\right\}
$$

Difference variance is used to measure the spread (concerning the mean) in distributing the grayscale differences in the image. The difference variance is calculated using equation 13.

$$
\text { Difference Variance }=\sum_{i=2}^{2 N_{g}}\left(i-\left[\sum_{i=2}^{2 N_{g}} i p_{x-y}(i)\right]\right)
$$

$N_{g}$ is the number of gray levels, $p(i, j)$ is the shared probability distribution of the pixel pair with gray level $i$ and gray level $j . \mu$ is the average of the pixel values and $\sigma$ is the standard deviation.

In addition to textural characteristics, the colour features will also be extracted to assist in obtainin colour features in peanut plant diseases. The extracted colour feature is the mean in the HSV colour space. The conversion of RGB to HSV images can be calculated using equation 14 [16].

$$
\begin{aligned}
& r=\frac{R}{R+G+B}, \quad g=\frac{G}{R+G+B}, \quad b=\frac{B}{R+G+B} \\
& V=\max (r, g, b) \\
& H=\left\{\begin{array}{cc}
\frac{0}{60(g-b)} & \text { if } S=0 \\
S * V *\left[2+\frac{(b-r)}{S * V}\right] & \text { if } V=r \\
60 *\left[4+\frac{(r-g)}{S * V}\right] & \text { if } V=b \\
0 & \text { If } V=0
\end{array}\right. \\
& S=\left\{\begin{array}{cc}
V-\frac{\min \left(r_{n}, b\right)}{V} & \text { If } V>0
\end{array}\right. \\
& H=H+360 \text { If } H<0
\end{aligned}
$$

Obtaining the mean HSV value from the image can be calculated using equation 15 .

$$
\begin{aligned}
& I_{H}=\frac{H}{H+S+V} \\
& I_{S}=\frac{S}{H+S+V} \\
& I_{V}=\frac{V}{H+S+V}
\end{aligned}
$$

Where I is the intensity, while $\mathrm{H}, \mathrm{S}$, and $\mathrm{V}$ are Hue, Saturation, and Value, respectively.

\subsection{Classification}

Classification is the process of determining a model or function that describes or distinguishes a concept or data class to estimate an object's class. The purpose of classification is to recognise the image by classifying the characteristics it possesses. In the classification process, there are two phases, particularly the training phase and the testing phase. The training phase is part of the data that has been recognised by the data class to form a thinking model. As for the testing phase, the model that has been formed is tested with some other data to determine the model's accuracy. 
The Support Vector Machine (SVM) method is chosen in this study to be used in the classification process. The SVM method is a supervised learning classification method to determine the best hyperplane used to separate two classes in the input space. The best hyperplane is the middle between the object and two classes, particularly the positive and negative classes. The approach to acquire the best hyperplane is to measure the hyperplane margin and determine its maximum point. Figure 2 shows an illustration of the optimal hyperplane that separates two data classes, a positive class, and a negative class.

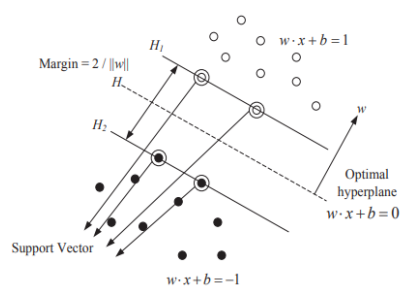

Figure 2. Illustration of a Support Vector Machine

The SVM method has a weakness of only able to classify two classes. Therefore this research will use the development of the SVM method, i.e. the Multiclass SVM method, with the strategy used is the Directed Acyclic Graph Support Vector Machine (DAGSVM), which can classify more than two data classes. In the DAGSVM method, training is carried out by building $\mathrm{N}(\mathrm{N}-1) / 2$ binary SVM classification models the same as the one-against-one (OAO) method. Meanwhile, at the testing stage, it is only $\mathrm{N}-1$ times. Figure 3 shows an illustration of the DAGSVM classification with five classes.

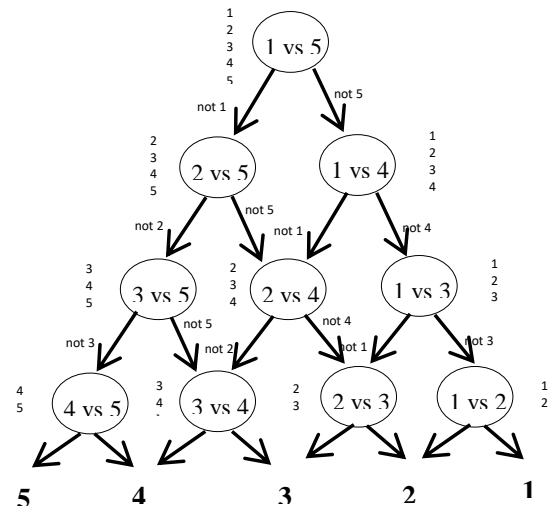

Figure 3. Illustration of DAGSVM for the 5 class classification

The DAGSVM method consists of $\mathrm{N}(\mathrm{N}-1) / 2$ of two kinds of classifiers. Each classifier correspondence with two classes distributed in the N structure. In DAGSVM, there is a node in the top layer called the root node. The two nodes are in the second layer and forward, where the $\mathrm{j}$ layer has as many as $\mathrm{i}$ nodes. The total number of nodes depends on $\mathrm{N}(\mathrm{N}-1) / 2$. Each node represents one decision function. Each node will classify the processed data into the next layer using the SVM algorithm. The result of the decision in the form of class is actually in the last layer [17].

\section{Results and Discussion}

In this research, a dataset of 402 images was used, which were collected through an image acquisition process using a Samsung J8 mobile camera, with details of 100 images of leaf spot class, 100 images of leaf rust class, 72 images of eyespot class, 100 images of normal leaf class, and 30 images of other leaf class. This image dataset will be inputted into the program, and then it will undergo the preprocessing stage, where the image will be resized to $635 \times 439$ pixels. This resized image will be used in the segmentation process to obtain the Region Of Interest (ROI) part, which is the diseased part of the peanut leaf image. Figure 4 shows the image from the segmentation process.

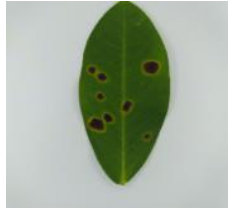

a

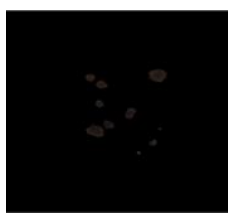

d

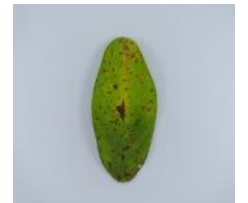

b

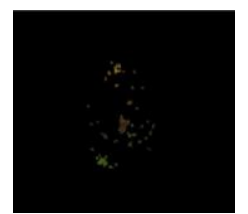

e

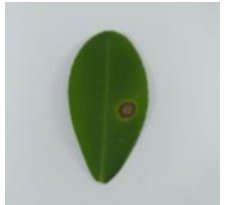

C

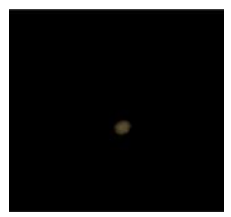

f
Figure 4. Original image of peanut leaves: (a) Leaf spots, (b) Leaf rust, (c) Eyespots, Segmentation results image (d) Leaf spots, (e) Leaf rust, (f) Eyespots

After the segmented image was obtained, the following process was feature extraction to obtain the texture and colour features of the peanut leaf image. In the feature extraction process, the segmented image will be converted into a grayscale image for the GLCM texture feature extraction process. It will be converted into the HSV colour space for the colour feature extraction process. The GLCM process will use distance as $d=1$, and four angular orientations will be used, i.e. $0^{\circ}{ }_{x} 45^{\circ}{ }_{0} 90^{\circ}$ dan $135^{\circ}$. The extracted texture features are ASM, contrast, IDM, correlation, entropy, variance, sum average, sum entropy, sum variance, difference entropy, and difference variance. As for the extraction of colour features, three features were extracted, namely the mean $\mathrm{H}$, mean $\mathrm{S}$, and mean V. Thus, in this study, there were 14 features used to obtain the features of the image of peanut leaves. Table 1 shows the results of the extraction of GLCM texture features and HSV colour features.

Table 1. Extraction Results of GLCM and HSV Features

\begin{tabular}{|c|c|c|c|c|c|}
\hline \multirow{2}{*}{ Image } & \multirow{2}{*}{ Features } & \multicolumn{4}{|c|}{ Angle (degrees) } \\
\cline { 3 - 6 } & & $\mathbf{0}$ & $\mathbf{4 5}$ & $\mathbf{9 0}$ & $\mathbf{1 3 5}$ \\
\hline \multirow{3}{*}{$\mathrm{ASM}$} & 0.8653 & 0.8558 & 0.8635 & 0.8565 \\
\cline { 2 - 6 } & Contrast & 0.0262 & 0.0362 & 0.0284 & 0.0355 \\
\cline { 2 - 6 } & IDM & 0.9871 & 0.9821 & 0.9860 & 0.9824 \\
\cline { 2 - 6 } & Corelation & 0.7627 & 0.6729 & 0.7424 & 0.6790 \\
\cline { 2 - 6 } & Entropy & 0.3222 & 0.3481 & 0.3279 & 0.3465 \\
\cline { 2 - 6 } & Variance & 1.1419 & 1.1422 & 1.1421 & 1.1434 \\
\cline { 2 - 6 } & $\begin{array}{c}\text { Sum } \\
\text { average }\end{array}$ & 2.1167 & 2.1169 & 2.1164 & 2.1169 \\
\cline { 2 - 6 } & $\begin{array}{c}\text { Sum } \\
\text { entropy }\end{array}$ & 0.3036 & 0.3226 & 0.3076 & 0.3215 \\
\cline { 2 - 6 } & Sum & 3.4818 & 3.4042 & 3.4636 & 3.4090 \\
\hline
\end{tabular}




\begin{tabular}{|c|c|c|c|c|}
\hline variance & & & & \\
\hline $\begin{array}{c}\text { Difference } \\
\text { entropy }\end{array}$ & 0.1206 & 0.1551 & 0.1285 & 0.1529 \\
\hline $\begin{array}{c}\text { Difference } \\
\text { variance }\end{array}$ & 0.0262 & 0.0362 & 0.0284 & 0.0355 \\
\hline Mean $\mathrm{H}$ & 0.1410 & 0.1410 & 0.1410 & 0.1410 \\
\hline Mean S & 0.3843 & 0.3843 & 0.3843 & 0.3843 \\
\hline Mean V & 0.1711 & 0.1711 & 0.1711 & 0.1711 \\
\hline ASM & 0.2504 & 0.2324 & 0.2483 & 0.2222 \\
\hline Contrast & 0.1985 & 0.2312 & 0.1856 & 0.2549 \\
\hline IDM & 0.9121 & 0.8891 & 0.9117 & 0.8773 \\
\hline Corelation & 0.8194 & 0.7811 & 0.8306 & 0.7585 \\
\hline Entropy & 1.6007 & 1.6592 & 1.5943 & 1.6980 \\
\hline Variance & 4.9118 & 5.0088 & 4.8686 & 5.0146 \\
\hline $\begin{array}{c}\text { Sum } \\
\text { average }\end{array}$ & 4.2098 & 4.2747 & 4.1970 & 4.2747 \\
\hline $\begin{array}{c}\text { Sum } \\
\text { entropy }\end{array}$ & 1.4413 & 1.4889 & 1.4556 & 1.5110 \\
\hline $\begin{array}{c}\text { Sum } \\
\text { variance }\end{array}$ & 9.6642 & 9.6399 & 9.5180 & 9.4936 \\
\hline $\begin{array}{c}\text { Difference } \\
\text { entropy }\end{array}$ & 0.4926 & 0.5459 & 0.4808 & 0.5748 \\
\hline $\begin{array}{c}\text { Difference } \\
\text { variance }\end{array}$ & 0.1985 & 0.2312 & 0.1856 & 0.2549 \\
\hline Mean $\mathrm{H}$ & 0.0984 & 0.0984 & 0.0984 & 0.0984 \\
\hline Mean S & 0.4692 & 0.4692 & 0.4692 & 0.4692 \\
\hline Mean V & 0.2934 & 0.2934 & 0.2934 & 0.2934 \\
\hline
\end{tabular}

The subsequent process is the classification to classify the five classes of leaf conditions used in this study. This classification process gains input from the extraction of GLCM texture features and HSV colour characteristics with 14 features. The sharing proportion of training data and test data used in the classification process is $70 \%$ for training data and $30 \%$ for test data, with 282 images as training data and 120 images as test data. The classification method used is Multiclass SVM with the DAGSVM strategy. The kernel used to test the DAGSVM method in this study compares the use of two types of kernels, namely linear kernels and polynomial kernels. For the performance evaluation of the classification model, the calculated parameter is accuracy. Accuracy is calculated using equation 16.

$$
\text { Accuration }=\frac{T P+T N}{T P+T N+F P+F N} \times 100 \%
$$

Where TP is True Positive, TN is True Negative, FP is False Positive, and FN is False Negative.

Table 2 shows the performance of the classification results using the multiclass SVM method with the DAGSVM strategy on the polynomial kernel with an angle of 0 degrees.

Table 2. Classification Performance for Polynomial Kernels, 0 degrees angle

\begin{tabular}{|c|c|c|c|c|c|c|}
\hline No. & Diseases & $\mathbf{T P}$ & TN & FP & FN & $\begin{array}{c}\text { Accuration } \\
(\%)\end{array}$ \\
\hline 1 & $\begin{array}{l}\text { Leaf } \\
\text { Spot }\end{array}$ & 29 & 90 & 0 & 1 & 99.1667 \\
\hline 2 & $\begin{array}{l}\text { Leaf } \\
\text { Rust }\end{array}$ & 30 & 87 & 3 & 0 & 97.5000 \\
\hline 3 & Eyespot & 19 & 99 & 0 & 2 & 98.3333 \\
\hline 4 & $\begin{array}{c}\text { Normal } \\
\text { Leaf }\end{array}$ & 30 & 90 & 0 & 0 & 100 \\
\hline 5 & $\begin{array}{l}\text { Other } \\
\text { Leaf }\end{array}$ & 9 & 111 & 0 & 0 & 100 \\
\hline
\end{tabular}

Figure 5 shows a graph of the performance of the multiclass SVM classification results with the DAGSVM strategy using a polynomial kernel with an angles of $0,45,90$, and 135 degrees.

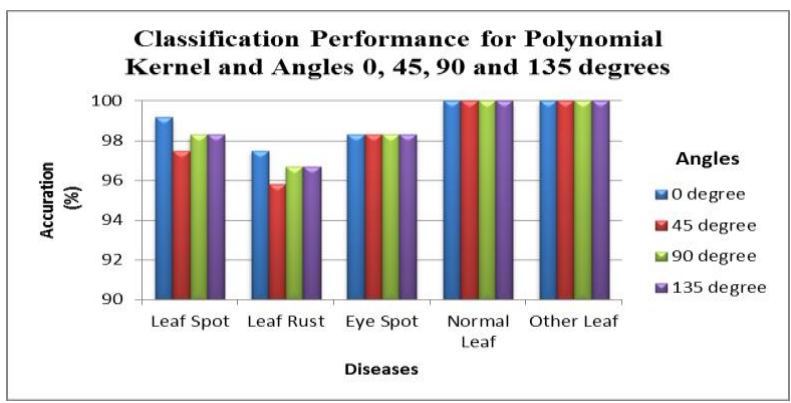

Figure 5.Graph of Classification Performance Results for Polynomial Kernel, Angles 0, 45, 90, and 135 degrees

Table 3 shows the performance of the classification results using the multiclass SVM method with the DAGSVM algorithm on a linear kernel with an angle of 0 degrees.

Table 3. Performance Classification for Linear Kernel, Angle 0 degrees

\begin{tabular}{|c|c|c|c|c|c|c|}
\hline No. & Diseases & TP & TN & FP & FN & $\begin{array}{c}\text { Accuration } \\
(\mathbf{\%})\end{array}$ \\
\hline 1 & $\begin{array}{c}\text { Leaf } \\
\text { Spot }\end{array}$ & 28 & 90 & 0 & 2 & 98.3333 \\
\hline 2 & $\begin{array}{c}\text { Leaf } \\
\text { Rust }\end{array}$ & 30 & 85 & 5 & 0 & 95.8333 \\
\hline 3 & Eyespot & 18 & 99 & 0 & 3 & 97.5000 \\
\hline 4 & $\begin{array}{c}\text { Normal } \\
\text { Leaf }\end{array}$ & 30 & 90 & 0 & 0 & 100 \\
\hline 5 & $\begin{array}{c}\text { Other } \\
\text { Leaf }\end{array}$ & 9 & 111 & 0 & 0 & 100 \\
\hline
\end{tabular}

Figure 6 shows a graph of the performance of the SVM multiclass classification results with the DAGSVM strategy using a linear kernel with an angles of 0, 45, 90, and 135 degrees. 


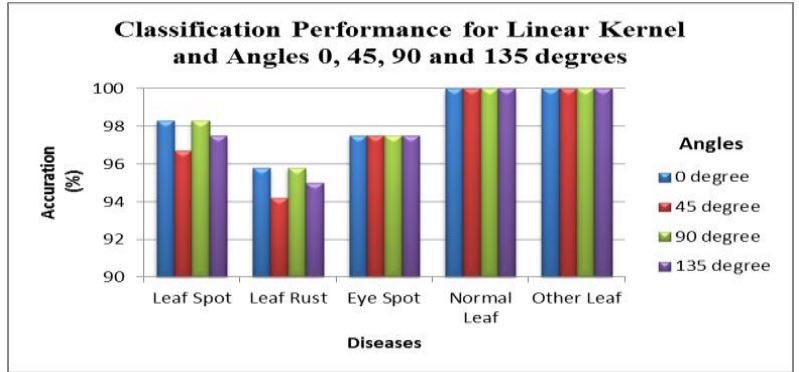

Figure 6. Graph of Classification Performance Results for Linear Kernel, Angles 0, 45, 90, and 135 degrees.

Table 4 shows the confusion matrix results from the results of the SVM multiclass classification system with the DAGSVM algorithm on a polynomial kernel with an angle of 0 degrees.

Table 4. Confusion Matrix Classification Results for Polynomial Kernel, Angle 0 degrees (\%)

\begin{tabular}{|c|c|c|c|c|c|}
\hline & $\begin{array}{c}\text { Leaf } \\
\text { Spot }\end{array}$ & $\begin{array}{c}\text { Leaf } \\
\text { Rust }\end{array}$ & Eyespot & $\begin{array}{c}\text { Normal } \\
\text { Leaf }\end{array}$ & $\begin{array}{c}\text { Other } \\
\text { Leaf }\end{array}$ \\
\hline $\begin{array}{c}\text { Leaf } \\
\text { Spot }\end{array}$ & 96.7 & 3.3 & 0 & 0 & 0 \\
\hline $\begin{array}{c}\text { Leaf } \\
\text { Rust }\end{array}$ & 0 & 100 & 0 & 0 & 0 \\
\hline Eyespot & 0 & 9.5 & 90.5 & 0 & 0 \\
\hline $\begin{array}{c}\text { Normal } \\
\text { Leaf }\end{array}$ & 0 & 0 & 0 & 100 & 0 \\
\hline $\begin{array}{c}\text { Other } \\
\text { Leaf }\end{array}$ & 0 & 0 & 0 & 0 & 100 \\
\hline
\end{tabular}

Based on table 4, the results of the confusion matrix for kernel polynomial with an angle of 0 degrees indicate that the system is able to classify peanut leaf diseases appropriately, i.e. $96.7 \%$ as leaf spot class from 30 data, $100 \%$ as leaf rust class from 30 data, $90.5 \%$ as eyespot class from 21 data, $100 \%$ as normal leaf class from 30 data and $100 \%$ as other leaf class from 9 data.

Table 5 shows the confusion matrix results from the results of the SVM multiclass classification system with the DAGSVM algorithm on a linear kernel with an angle of 0 degrees.

Table 5. Confusion Matrix Classification Results for Linear Kernel, Angle 0 degrees (\%)

\begin{tabular}{|c|c|c|c|c|c|}
\hline & $\begin{array}{c}\text { Leaf } \\
\text { Spot }\end{array}$ & $\begin{array}{c}\text { Leaf } \\
\text { Rust }\end{array}$ & Eyespot & $\begin{array}{c}\text { Normal } \\
\text { Leaf }\end{array}$ & $\begin{array}{c}\text { Other } \\
\text { Leaf }\end{array}$ \\
\hline $\begin{array}{c}\text { Leaf } \\
\text { Spot }\end{array}$ & 93.3 & 6.7 & 0 & 0 & 0 \\
\hline $\begin{array}{c}\text { Leaf } \\
\text { Rust }\end{array}$ & 0 & 100 & 0 & 0 & 0 \\
\hline Eyespot & 0 & 14.3 & 85.7 & 0 & 0 \\
\hline $\begin{array}{c}\text { Normal } \\
\text { Leaf }\end{array}$ & 0 & 0 & 0 & 100 & 0 \\
\hline $\begin{array}{c}\text { Other } \\
\text { Leaf }\end{array}$ & 0 & 0 & 0 & 0 & 100 \\
\hline
\end{tabular}

Based on table 5, the results of the confusion matrix for kernel linear with an angle of 0 degrees indicate that the system can classify peanut leaf disease accurately, i.e. $93.3 \%$ as leaf spot class from 30 data, $100 \%$ as leaf rust class from 30 data, $85.7 \%$ as eye spot class from 21 data, $100 \%$ as normal leaf class from 30 data and $100 \%$ as other leaf class from 9 data.

\section{Conclusion}

The disease detection system in peanut leaves has been designed successfully in this research. Based on the results of the research, the classification system of peanut leaf disease using polynomial kernels obtained the highest accuracy at pixel proximity (distance) of 1 and in the GLCM direction of 0 degrees with an accuracy value of $99.1667 \%$ for leaf spot class, $97.5 \%$ for leaf rust class, $98.8333 \%$ for eyespot class, $100 \%$ for normal leaf class and $100 \%$ for other leaf class. Whereas for the classification of peanut leaf disease with linear kernels, the highest accuracy was obtained at the pixel proximity (distance) of 1 and the GLCM 0 and 90 degrees with an accuracy value of $98.3333 \%$ for leaf spot class, $95.8333 \%$ for leaf rust class, $97.5 \%$ for eyespot class, $100 \%$ for normal leaf classes and $100 \%$ for other leaf classes. Based on the accuracy results obtained, the SVM multiclass classification model with the DAGSVM approach using a polynomial kernel provides the best accuracy results compared to the use of a linear kernel.

\section{REFERENCES}

[1] Hardaningsih, S., and Sumartini. 2015. Penyakitpenyakit yang disebabkan oleh Jamur pada Kacang Tanah dan Cara Pengendaliannya. Monograf Balitkabi Malang.

[2] Rahayu, M., and Sumartini. 2015. Status Penyakit Utama pada Tanaman Kacang Tanah dan Kacang Hijau di Lahan Sub Optimal Jawa Timur.

[3] Siqueira, F.R.D., Schwortz, W.R., and Pedrini, H. 2013. Multiscale Gray Level Co-occurrence Matrices for Texture Description. Neurocomputing, Volume 120, pp.336-345.

[4] Prasetyo, E. 2014. Data Mining - Mengolah Data menjadi Informasi menggunakan MATLAB. Penerbit Andi Yogyakarta.

[5] Valerina, F. 2012. Perbandingan Local Binary Pattern dan Fuzzy Local Binary Pattern untuk Ekstrasksi Ciri Tumbuhan Obat. Institut Pertanian Bogor.

[6] Putra, R.P. 2018. Klasifikasi Penyakit Tanaman Kedelai melalui Tekstur Daun dengan Metode Gabor Filter dan Multiclas Support Vector Machine. Universitas Brawijaya.

[7] Masazhar, A.N.I., and Mahanijah,Md.K. 2017. Digital Image Processing Technique for Palm Oil Leaf Disease Detection using Multiclass SVM Classifier. IEEE International Conference on Smart Instrumentation, Measurement and Application (ICSIMA).

[8] Ghyar, B.S., and Birajdar, G.K. 2017. Computer Vision Based Approach to Detect Rice Leaf Diseases using Texture and Color Descriptors. International Conference on Inventive Computing and Informatics (ICICI 2017). IEEE:1074-1078.

[9] Krithika, P., and Veni, S. 2017. Leaf Disease Detection on Cucumber Leaves using Multiclass Support Vector Machine. WISPNET 2017 Conference. IEEE:1276-1281. 
[10] Permata, E., Purnama, I.K.E. and Purnomo, M.H. 2013. Klasifikasi Jenis dan Fase Parasit Malaria Plasmodium Falciparum dan Plasmodium Vivax dalam Sel Darah Merah menggunakan Support Vector Machine OneAgainst-One. SEMNASTEKNOMEDIA ONLINE.

[11] Ramadhani., Arnia., and Muharar, R. 2020. Klasifikasi Motif Tekstil menggunakan Support Vector Machine Multi Kelas. JTIIK. Universitas Brawijaya. Vol.7, no.1, February 2020. p.9-108

[12] Saini, I., Singh, D., and Khosla, A. 2014. Electrocardiogram Beat Classification using Emprical Mode Decomposition and Multiclass Directed Acyclic Graph Support Vector Machine. Computers and Electrical Engineering, 40(5):1174-1787.

[13] Kadir, A., and Susanto, A. 2013. Teori dan Aplikasi Pengolahan Citra. Penerbit Andi Yogyakarta.

[14] Ponmoli, K.M., and Selvamuthukumaran, S. 2014 Analysis of Face Recognition using Manhattan Distance Algorithm with Image Segmentation. IJCSMC. Vol.3, Issue.7, July 2014. p.18-27

[15] Prastyaningsih., Yunita., and Fatichah, C. 2016 Kombinasi Fitur Multiscale Gray Level Co-Occurrence Matrices dan Warna untuk Sistem Temu Kembali Citra Gerabah di Museum Majapahit Trowulan. Institut Teknologi Surabaya. Thesis.

[16] Rulaningtyas, R., Suksmono, A.B., Mengko, T.L.R., and Saptawati, G.A.P. 2015. Segmentasi Citra Berwarna dengan Menggunakan Metode Clustering Patch untuk Identifikasi Mycrobacterium Tuberculosis. JBP. Vol.17, No. 1, Agustus 2015. Universitas Airlangga.

[17] Cholissodin, I., Kurniawati, M., Indriati., and Arwani, I. 2014. Classification of Campus E-Complaint Documents using Directed Acyclic Graph Multi-Class SVM Based on Analytic Hierarchy Process. ICACSIS. 